\title{
A STUDY ON THE IMPLEMENTATION OF NANOTECHNOLOGY IN ENHANCING THE ENVIRONMENTAL CHANGES
}

\author{
Sejal THAKUR \\ thakursejal22@gmail.com \\ Satya Sandeep CHAGANTI \\ chsatyasandeep@gmail.com \\ SANDIP UNIVERSITY, NASHIK, INDIA
}

\begin{abstract}
The report takes a survey of five crucial areas where nanotechnology is implied. It includes areas of economy through hydrogen, electricity generation with the help of solar cells, fuel additives, batteries, and super capacitors, and insulators. In concern with fuel additives, with the help of nanoparticle, the efficiency of fuel of diesel engines was increased by up to $5 \%$, which produced about three-million metric tons of $\mathrm{CO}_{2}$ in the UK per year. The study also cautions that this efficiency of fuel additives also led to the release of toxic nanoparticles openly in the environment. Due to small in size, no control could be applied to the restriction of the emission of nanoparticles. Thus, this exhaust gas proves to be harmful to humans. Although a diesel engine, if properly maintained can last up to 300,000-600,000 miles. In comparison with diesel engines, electric engines produce very little efficiency. Solar cells are still a promising area in nanotechnology since they have shown the results of a decrease in the cost while solar cells were produced and have enabled more cell production.
\end{abstract}

\section{KEYWORDS:}

Environment, nanotechnology, nanotechnology applications, hydrogen economy, nanoparticles for environment

\section{Introduction}

If solar energy meets $1 \%$ of the demands for electricity then in a year, around 1 to 1.5 million tons of carbon dioxide could be saved. The solar energy incorporated with nanotechnology has surely proved to be a boon to some extent, also solar cells are reaching out to supply most of the electricity demands. They are researched out in laboratories to practice in the commercial arena. 


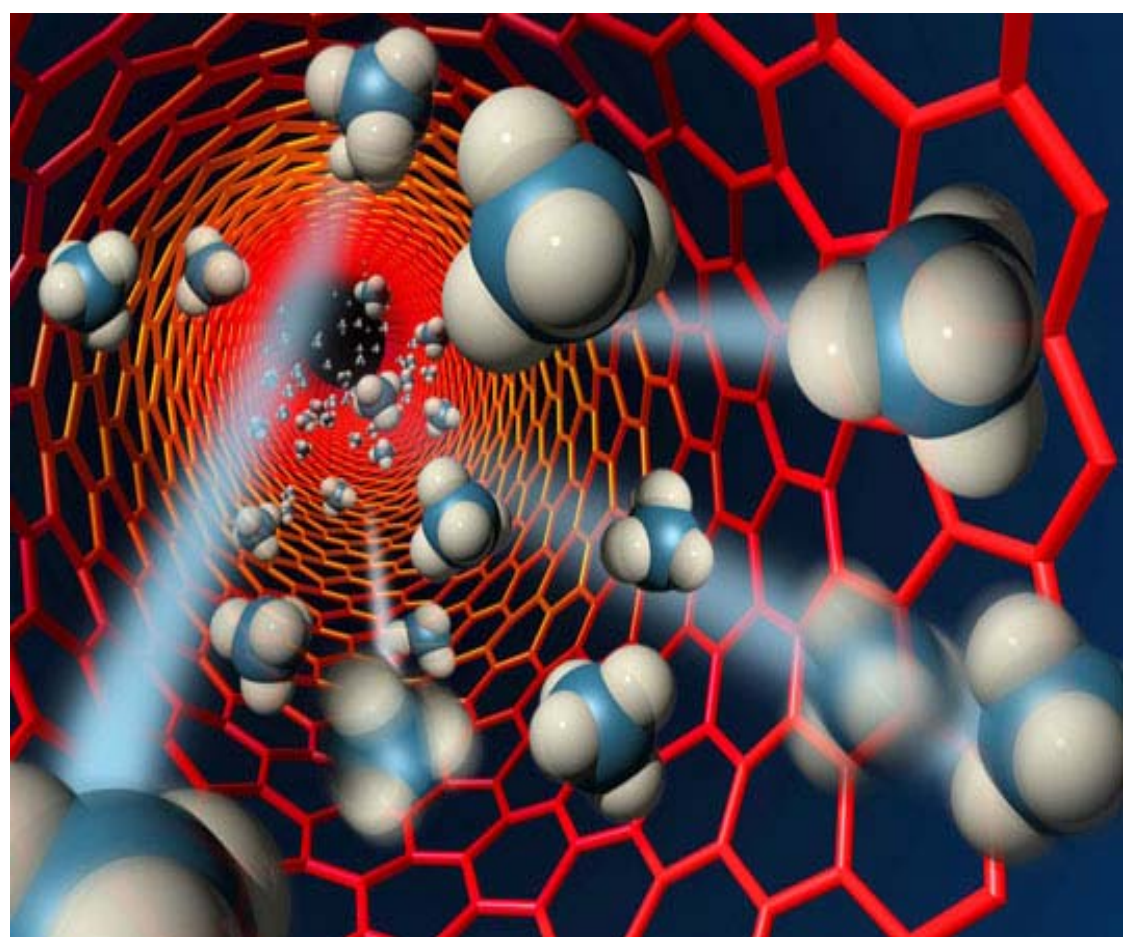

Figure no. 1. Filtration of molecules in Nanotube

(Source: Lawrence Livermore National Laboratory, 2010)

Hydrogen and oxygen are alternatives when there is no source to produce electricity. Some 40 years ago, hydrogen played an important role in storing as a fuel. It improved the efficiency of storage and also helped in developing various methods to produce hydrogen. To reduce fuel problems, to some extent fuel consuming vehicles are replaced by electric cars by using advance batteries that can drive up to 1100 miles in a single charge. Hence, electric cars are also tagged as zero-emission vehicles and have proved to be a boon. Also, nanotechnology is also used in these batteries in higher numbers to reduce the charge time problem and allow them to charge faster in a short duration.

Nanotechnology is also used in solidwalled buildings' insulation, in Frost \& Sullivan, and adding effective change that helps to reduce the $\mathrm{CO}_{2}$ emission up to 3 million tons per year (Ahmed, Hyder, Liaqat \& Scholz, 2019).

\section{How can nanotechnology be used} to help limit climate change?

Climate change has become a serious issue in the past few decades. The reasons to be noted for this are changes in solar output, depletion of the ozone layer due to the production of harmful pollutants, volcanism and human activities that have developed the threating issue of global warming. The greenhouse gases are depleting and hence the planet is losing its temperature regulation. About $0.56{ }^{\circ} \mathrm{C}$ temperature increase is occurring per year. According to a survey, $70 \%$ of people think that global warming occurred due to no control of human activities. If these activities don't come to halt then by $2050,83 \%$ carbon dioxide emission will lead to $11.6 \%$ of temperature rise as compared to today's temperature. The challenge for climate control is to slow down the rising $\mathrm{CO}_{2}$ emission in the atmosphere. 


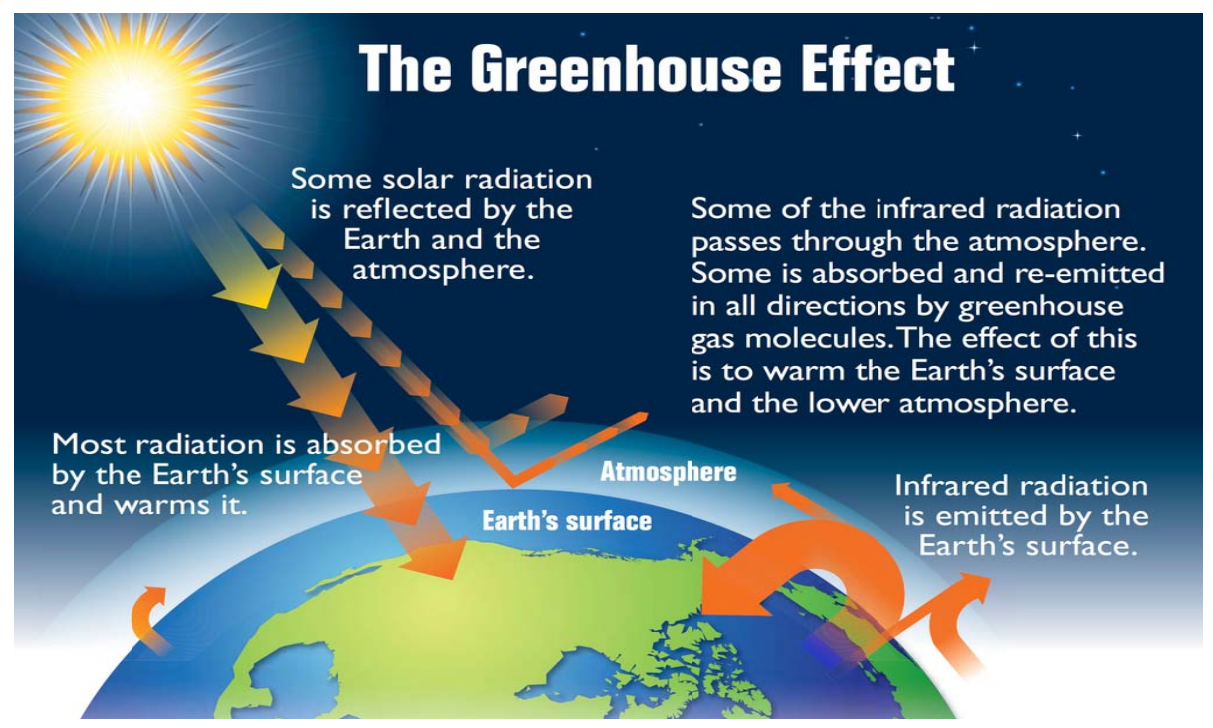

Figure no. 2. The Greenhouse Effect

(Source: US EPA Climate Change Indicators in the United States, 2012)

\section{control}

2.1. Role of plants in temperature

The carbon dioxide emissions should be reduced even though it's beneficial for the planet because the carbon dioxide than comes as emission from vehicles have other gases like nitrogen, carbon monoxide and unburnt petrol with $\mathrm{CO}_{2}$. The amount of $\mathrm{CO}_{2}$ as compared to the other gases is very low and also very difficult as well as too expensive to separate while the other gases contribute the maximum amount for increasing the pollution level in the atmosphere. To overcome this, we need plants because plants take carbon dioxide from all the emitted sources and sunlight during photosynthesis and produce oxygen. During the daytime, $\mathrm{CO}_{2}$ is taken by the plants and oxygen is released through photosynthesis. At night, due to respiration, only half the amount of carbon dioxide is released. This states that plants absorb more than they emit. In the process of respiration, plants break down glucose food in the presence of oxygen to get energy. This break down results in the formation of $\mathrm{CO}_{2}$ and water (Shi et al., 2015).

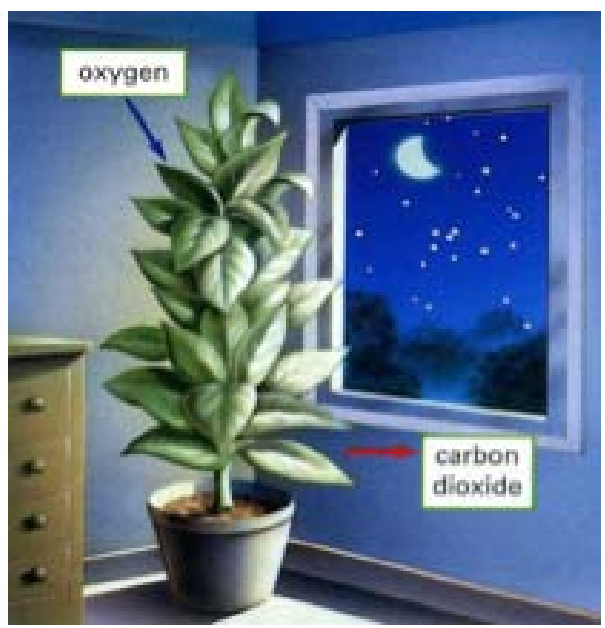

Figure no. 3. Respiration in plants

(Source: Santigosa) 
It is challenging for the government and individuals to depend on innovation of technologies without sacrificing economic growth to help us rescue the climatic situation. The takes \$7billion+ for the industries to project this. The new era of molecular manufacturing has sufficient quantity for everyone. The innovation of nanobots has been a boon to a certain extent. They have been the game-changing devices. If nanobots shape themselves into different devices, then the carbon emitted during manufacturing could be reduced severely. Another way to reduce emissions is by practicing artificial photosynthesis. This process comes under molecular manipulation. One can also produce hydrocarbon fuels with individual molecules by taking energy from the sun.

Graphene behaves as a strong nanomaterial, and with the combination of 2D materials, it has been implied in cathodes of the battery. The purpose of this change was to increase the storage capacity of energy in Lithium-ion batteries. If these materials are used for construction purpose, then there will be less extraction of resource and thus the emission of carbon footprints will be reduced.

Solar panels have also proven to be helpful to nanotechnology in helping with combating climate change. It is currently examined by the Shockley-Queisser limit that the efficiency of solar panels is limited. The reason behind this is, the bandgap present in the silicon semiconductor is not aligned precisely with the peak wavelength of incoming rays by the sun. These rays interact with the matter, this means that the matter has to interact with all the airborne particles, ozone and several other gases present in the atmosphere.

\subsection{Plants boost the carbon uptake}

A new study has found that the temperature of the leaf is regulated by the plants independently with the help of the surrounding temperature of the air. Because of this, a trait increases carbon uptakes through photosynthesis. This research, therefore, helps to predict climate change impacts. It combines the theory for leaf energy flows with globally distributed temperature data. For diverse plants, the leaves do not match with the surrounding air temperature but thermoregulations (Sarfaraz, Hussain, Sabir, Fekih, Ditta \& Xing, 2019).

\subsection{Classification and sources of pollutants}

Natural resources are being exploited for long ago. "Environmentalism" was the moment started by Americans to make people aware of the environmental crisis. Many new processes were found out to induce the emission of pollutants.

\subsection{Air pollutants}

The clean air act was passed in the year 1970 by the US to check the quality of air and stop air pollution. By this act, an organization was set called National Ambient Air Quality Standards (NAAQS). According to the survey done by this organization, the commonly found pollutants all over the country were categorized. These pollutants were termed as criteria pollutants and it included ozone, airborne particulates, carbon monoxide, lead, carbon dioxide, and nitrogen oxide. Then the organization focused on challenges caused due to air pollutants which included ozone are carbon monoxide, airborne toxins, sulphur dioxide, airborne particulates, indoor air pollutants, and acid deposition (Godish, 1989).

\subsection{Ozone and carbon monoxide}

Ozone is formed when 3 naturally occurring oxygen atoms are combined together. It is produced when sunlight triggers chemical reactions between the gases occurring in atmosphere and pollutants such as Volatile Organic Compounds (VCOs) and nitrogen oxides. 


\subsection{Acid decomposition}

It is a serious environmental crisis occurring in the world. When coal is burned, sulphur dioxide is emitted in the atmosphere. When these sulphur dioxides interact with nitrogen oxides emitted by motor vehicles, it gives rise to acid decomposition. During rain, these decompositions fall on the Earth in the form of acid rain (Nakamura, 2018).

\subsection{Water pollutants}

Water pollutants destroyed the aquatic and marine ecosystem. People also lost the source of aesthetic water supply. Basic sources of drinking water such as groundwater, tap water, surface water, are contaminated due to pollution. Many reports were reported with the problem of contaminated wells. These pollutants affected humans, plants, animals and also affected internationally (Motte, Vanneste \& Beekman, 2019).

\subsection{International effect}

In Japan, contamination of seawater with organic mercury was accumulated in fishes that were consumed by humans these lead to a severe human neurological disorder called Minamata disease e.g.: a pregnant woman who ate these fishes gave birth to infants who were severely impaired with neurology (Mattsson, Hansson \& Cedervall, 2018).

Nowadays fullerenes, nanometre scaled particles, and carbon nanotubes are incorporated to produce composite materials that improved electrical conductivity and catalytic activity. It also has self-cleaning capability and antimicrobial properties. Today, nanoparticles are also widely used in slurries that are used for polishing semiconductor chips. Researches are still focusing on making tiny bacterium size devices and machines called nanobots that will be used to repair clogged arteries, kill cancer cells and even fire cellular damage that one causes due to aging. Nanobots will also have functions for fighting wide-body bacteria and viruses (Hull \& Bowman, 2018; Koliou et al., 2018).

\subsection{Nanomaterials and reduced pollution: \\ Nanomaterials have helped in mitigating pollution since they are efficient catalysts and can mostly be recyclable. Nanotechnology plays an economical role in commercialization and can completely replace present-day technologies.}

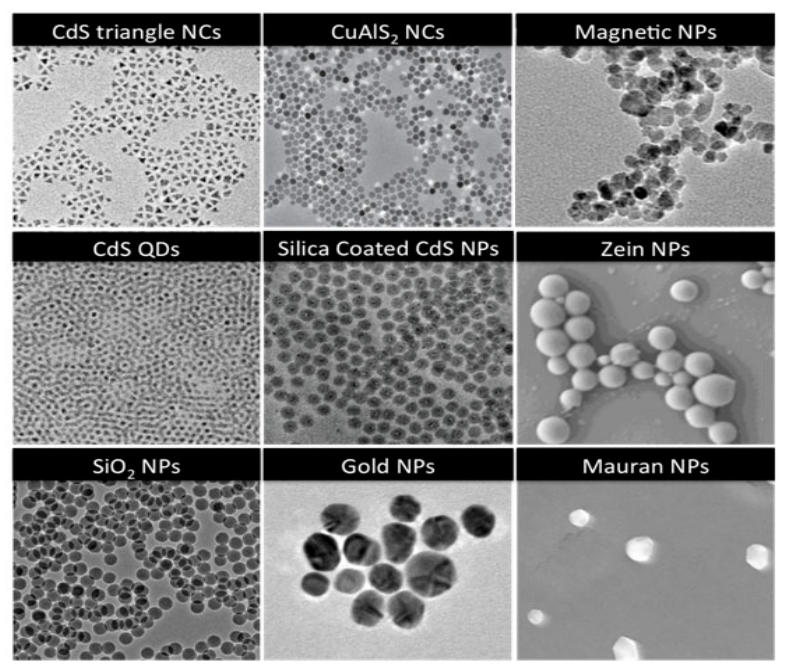

Figure no. 4. Size of Nanoparticles

(Source: Kumar, 2019) 


\subsection{Harvesting $\mathrm{CO}_{2}$}

Due to the rising atmospheric $\mathrm{CO}_{2}$ levels, nanoCO $\mathrm{O}_{2}$ harvesters are developed by the researchers that suck the carbon dioxide present in the atmosphere and thus deploys it for the purpose of industries.

Nanomaterials are used to convert carbon dioxide into alcohol which is a useful product. The materials can either be simple chemical catalysts or it can be photochemical in nature which works when the sunlight is present. The challenge faced by the researchers that can be proven as a holy grain in combating climate change is: how can $\mathrm{CO}_{2}$ be pulled out of the earth's atmosphere and converted to products that are useful. Nanoparticles having a large surface area to volume ratio that can interact with carbon dioxide in the atmosphere and convert them into many different things and it still has to be made economically viable. Various things right from metallic to carbon-based nanoparticles were used to make it cost-efficient, but still, they haven't proven it efficient for application on industrial scales.

Nano $\mathrm{CO}_{2}$ harvesters that can be used in the conversion of atmospheric $\mathrm{CO}_{2}$ into methanol with the help of sunlight and water, can be used as an engine fuel, as well as a solvent and an anti-freezing agent. Modified graphene oxide is used to wrap it, to form a diluent of ethanol around the spheres of magnetite and copper-zinc oxide and magnetite. It gets a look of a miniature golf ball and thus acts as a conventional catalyst in capturing $\mathrm{CO}_{2}$ more efficiently.

Nanoparticles having small size clump up and become inactive when used for a long time. Synthesizing nanoparticlebased materials can be also challenging because they cannot be easily converted into consistent size particles. Still, there are many methods practiced to improve them and make them efficient for several applications.

\subsection{Cleansing water}

The toxic dyes used in textile and leather industries can be captured by nanoparticles. Tanneries which are expelled from industries without treating, enter into natural water resources like deep tube wells and are even percolated in the groundwater. To solve this issue nanomaterial have been widely studied and it came out with a conclusion of capturing a large number of debris with the help of materials consisting of magnetic nanoparticles. These nanoparticles remove the pollutants and do not readily degrade in water. It can separate pollutants like chromium, arsenic, lead, and mercury from water. However, this approach still hasn't been cost-efficient in comparison with conventional water purification.
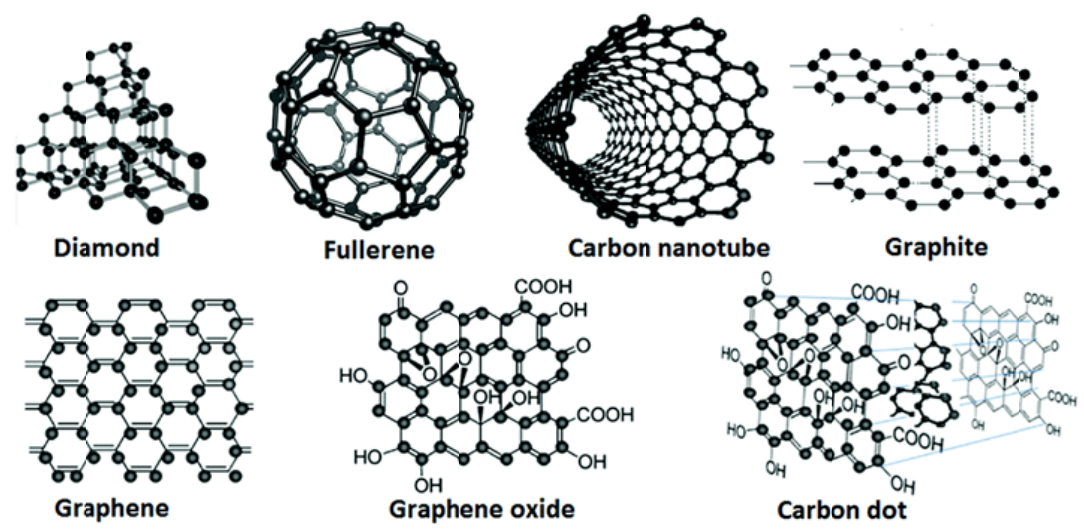

Figure no. 5. Carbon Nanoparticles

(Source: Properties and Applications of Carbon Nanoparticles, 2019) 
Nanomaterials are also used to clean the oil spilled in large water bodies. Researchers have invented a Nano sponge that is reusable to remove oil from contaminated seawater.

However, when the question comes up of cleaning the oil spilled seawater spread over miles, this technique has to be given a thought. A large synthesis of nanomaterials is required to practice this technique. Although scientists have still come up with solving this problem and can execute the ideas with the help of industrial partnerships and sufficient research.

\subsection{Accelerating digestion}

The application of nanotechnology is also found in the area of managing organic waste that becomes a significant reason for pollution if it's not handled properly. A large amount of biodegradable waste is generated by the agricultural farms and food industries and nanomaterials are used even here to manage it properly. Biodegradable waste is treated by using the oldest method of dumping into digester tanks. The anaerobic microbes filled in these tanks, consume the material and convert them into biogas fuel and solids. Then they are used as fertilizers. The major drawback of this method is that digestion takes place in a slow manner. But later it was discovered that when metal oxide nanoparticles were added to food waste digesters, the amount of biogas fuel was doubled as compared to digesters with did not contain these particles. The sludge of anaerobic digestion can be accelerated with the help of Nanoparticles thus it becomes efficient in duration and enhances the production of biogas.

The advantage of Iron oxide metal particles is that they are non-toxic, and can accelerate the rate of degradation without being harmful to the surrounding (Koliou et al., 2018).

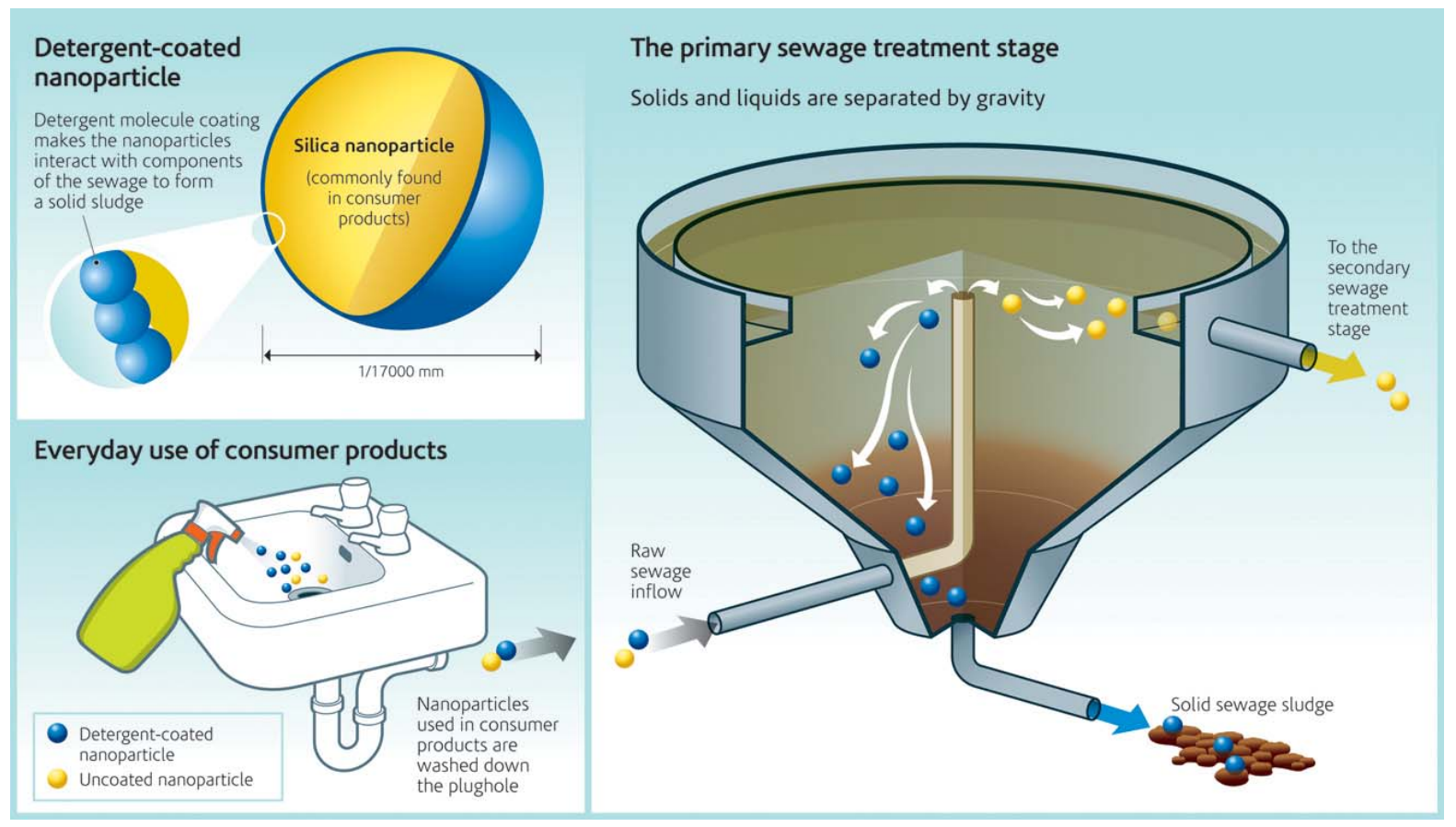

Figure no. 6. Nanoparticles in accelerating digestion

(Source: Managing nanoparticle waste in sewage, 2009) 


\subsection{Conventional and nano- technology-based methods \\ Variability in climate change such as} increasing temperature, irregular rainfall patterns, variability in seasons is also impacting diseases caused by mosquitoes such as malaria, dengue fever all over the world. Human health organization has estimated that about 1 million deaths occur per year by these vector-borne diseases. The green approaches are practiced to eradicate such diseases and save humans without harming the environment. These include both conventional (chemical, biological, environmental, mechanical, etc.) and nanotechnology-based (liposomes, polymer-based nanoparticles, and non-suspensions) for the eradication of mosquito-borne diseases (Keniger, Gaston, Irvine \& Fuller, 2013).

\subsection{Reducing the impacts of greenhouse gases}

The effects of greenhouse gases are caused when gases such as methane $\left(\mathrm{CH}_{4}\right)$, carbon dioxide $\left(\mathrm{CO}_{2}\right)$ and chlorofluorocarbon (CFCs) trap the heat in the atmosphere. These effects are causing the rise in Earth's temperature by $1.5-5^{\circ} \mathrm{C}$ per year which has led to the rise of sea levels up to $50 \mathrm{~cm}$ and also an increase in global rainfall and climate change (Sridharan, 2018).

\subsection{Agri-tech revolution with challenges and opportunities for nanotechnology}

Nanotechnology is providing to be an important driven in the Agri-tech revolution and is practicing a more sustainable and efficient agriculture system including food security (Willett et al., 2019).

\subsection{Emerging technologies to climate change}

The second-largest contributor methane $\left(\mathrm{CH}_{4}\right)$ results in an anthropogenic change in the climate. Since the preindustrial time, the emission of methane has tripled and is rising rapidly. The fact is that the population growth is directly proportional to food production, generation of energy and waste management. The effective abatement is largely restricted in high concentration sources which include landfills and anaerobic digesters. $\mathrm{CH}_{4}$ 's emission profile is not represented by these factors (Pratt \& Kevin, 2018).

\subsection{Nanotechnology tackling global water challenges}

To supply water that is harmless, pure and in adequate quantity is the global challenge. The treatment of water and desalination of water technologies remains ineffective in removing the trace of contaminants and the deployment of water treatment systems globally. Nanomaterials have made up for these technological shortcomings. The application of nanomaterials is being carried out for safe purification of water through nanotechnology (Mauter et al., 2018).

\subsection{Enhanced photocatalyst $\mathrm{CO}_{2}$ reduction}

The dual co-catalyst photocatalytic system of $\mathrm{RuO}_{2}$ and $\mathrm{Au}$ nanoparticles (NPS) was introduced in three dimensions of internal and external surfaces. The final photocatalyst of the hierarchically ordered TiO2-SiO2 (HTSO) framework was denoted as Au / HTSO. The optimal performance is shown by $\left(\mathrm{CO}_{2} \mathrm{PR}\right)$ and $\mathrm{Au} / \mathrm{HRTSO}(0.8$ $\%)$ in $\mathrm{CO}_{2}$ photocatalytic reduction. The yield of methane is twice than that of $\mathrm{Au} / \mathrm{HTSO}$ or HRTSO i.e. $(0.8 \%$ weight of the total percentage of $\mathrm{RuO}_{2}$ ). This advance configuration promotes transfer efficiency and enhances the performance of $\mathrm{CO}_{2} \mathrm{PR}$ which brings more yield of methane and solar light stimulation is eradicated (Dong, Hu, Xing \& Zhang, 2018).

\footnotetext{
3. How safe are nanoparticles for human health?

Although nanoparticles have the potential in solving up the environmental crisis up to some extent, they have been questioned for human health safety. The small size of these particles can result in a major drawback for human health.
} 
The evaluation of long-term effects has not been done yet. Researches come to a probability that the emission of nanoparticles in the free state from the emitters can be harmful to human health. The National Institute of Environmental Health Sciences, US and other research centres are funding for this evaluation and are trying to figure out how safe are nanoparticles on human health and the environment. They are trying to predict the effects of nanoparticles with the help of models. If these raised concerns deal adequately, nanomaterials could change the planet entirely and will help us in coping with environmental challenges in the coming years (Rai \& Biswas, 2018; Fabianoa, Reverberi \& Varbanov, 2019).

\section{Conclusions}

On $1^{\text {st }}$ January 2018, it was investigated that 420 gigatons of carbon dioxide are remaining on the planet from
780 gigatons, as surveyed in 1990. Till the start of 2019 , the $\mathrm{CO}_{2}$ number was reduced to 350 gigatons. With this emission levels, the remaining $\mathrm{CO}_{2}$ will be entirely depleted within 8.5 years. The amount of oxygen present on earth is $1,200,000$ billion metric tons (1200 gigatons) which will last up to 400 years.

$\mathrm{CO}_{2}$ regulates the earth's temperature is heavier than oxygen. It covers the fire like a blanket and traps heat. The amount of oxygen present on earth is $1,200,000$ billion metric tons which will last up to 400 years.

The liquid portion of $\mathrm{CO}_{2}$ that acts as a coolant in the atmosphere becomes gas, and due to the absorption of the latent heat of vaporization, the further portion of solid $\mathrm{CO}_{2}$ forms snow. Hence, nanotechnology is found to play a crucial role in stabilizing the serious climate change problem, if used properly. It can definitely be said that the next big thing is really small.

\section{REFERENCES}

Ahmed, T., Hyder, M. Z., Liaqat, I., \& Scholz, M. (2019). Climatic Conditions: Conventional and Nanotechnology-Based Methods for the Control of Mosquito Vectors Causing Human Health Issues. International journal of environmental research and public health. https://doi.org/10.3390/ijerph16173165.

Dong, C., Hu, S., Xing, M., \& Zhang, J. (2018). Enhanced photocatalytic $\mathrm{CO}_{2}$ reduction to $\mathrm{CH}_{4}$ over separated dual co-catalysts $\mathrm{Au}$ and $\mathrm{RuO}_{2}$. Nanotechnology, Vol. 29, Issue 15, available at: https://doi.org/10.1088/1361-6528/aaad44.

Fabianoa, B., Reverberi, A. P., \& Varbanov, P.S. (2019). Safety opportunities for the synthesis of metal nanoparticles and short-cut approach to workplace risk evaluation. Journal of Cleaner Production, Vol. 209, 297-308, https://doi.org/10.1016/j.jclepro.2018.10.161.

Godish, T. (1989). Indoor Air Pollution Control. $1^{\text {st }}$ Edition, USA: CRC Press.

Hull, M., \& Bowman, D. (2018). Nanotechnology Environmental Health and Safety. $3^{\text {rd }}$ Edition, Elsevier, eBook ISBN: 9780128135891.

Keniger, L. E., Gaston, K. J., Irvine, K. N., \& Fuller, R. A. (2013). What are the Benefits of Interacting with Nature?. International Journal of Environmental Research and Public Health, Vol. 10, Issue 3, 913-935.

Koliou, M., W. van de Lindt, J., Mcallister, T. P., Ellingwood, B. R., Dillard, M., \& Cutler, H. (2018). State of the research in community resilience: progress and challenges. Sustainable and resilient infrastructure. DOI: 10.1080/23789689.2017.1418547.

Kumar, S. (2019). Nanoparticles, available at: http://www.drsakthikumar.com/ nanoparticles.php, accessed on 20 October 2019.

Lawrence Livermore National Laboratory. (2010). Lawrence Livermore Laboratory Licenses Carbon Nanotube based Membranes for Desailation, available at: https://www.understan 
dingnano.com/carbon-nanotube-membrane.html, accessed on 23 November 2018.

Managing nanoparticle waste in sewage. (2009). available at: https://www.isis.stfc.ac.uk/ Pages/Managing-nanoparticle-waste-in-sewage.aspx, accessed on 20 October 2019.

Mattsson, K., Hansson, L., A., \& Cedervall, T. (2015). Nano-plastics in the aquatic environment. Environmental Science Processes \& Impacts, Issue 10.

Mauter, M. S., Zucker, I., Perreault, F., Werber, J. R., Kim, J. H., \& Elimelech, M. (2018). The Role of Nanotech in Tackling Global Water Challenges. Nature Sustainability, Vol. 1, 166-175.

Motte, H., Vanneste, S., \& Beeckman, T. (2019). Molecular and Environmental Regulation of Root Development, Annual Review of plant biology, Vol. 70, 465-488.

Nakamura, M., Etoh, S., Sakamoto, T., Nakamura, T., Xiao Jie, L., Miura, Y., Itatani, M., \& Hanakawa, T. (2018). Potential therapeutic effect of repetitive transcranial magnetic stimulation for tremor in Minamata disease: A case report. Journal of the Neurological Sciences, Vol. 388, 47-49.

Pratt, C., \& Kevin, T. (2018). Mitigating Methane: Emerging Technologies to Combat Climate Change's Second Leading Contributor. Environmental Science and Technology, available at: https://doi.org/10.1021/acs.est.7b04711, accessed on 20 October 2019.

Properties and Applications of Carbon Nanoparticles. (2019). available at: https:// www.cd-bioparticles.com/t/Properties-and-Applications-of-Carbon-Nanoparticles 61.html, accessed on 20 October 2019.

Rai, M., \& Biswas, J. M. (2018). Nanomaterials: Eco toxicity, Safety, and Public Perception. Switzerland: Springer Nature. https://doi.org/10.1007/978-3-030-05144-0

Santigosa, D. J. (2019). Plants respiration, fungi and mushrooms, available at: https://flowvella.com/s/3avw/0BCF7435-D258-48FC-831C-FA319449BBB4, accessed on 24 October 2019.

Sarfaraz, R., Hussain, A., Sabir, A., Fekih I., B., Ditta, A., \& Xing, S. (2019). Role of bio char and plant growth promoting rhizobacteria to enhance soil carbon sequestration-a review. Environmental Monitoring and Assessment, Vol. 191, 251. https://doi.org/10.1007/ s10661-019-7400-9.

Shi, K., Li, X., Zhang, H., Zhang, G., Liu, Y., Zhou, Y., Xia, X., Chen, Z., \& Yu, J. (2015). Guard cell hydrogen peroxide and nitric oxide mediate elevated CO2-induced stomatal movement in tomato. New Phytol, Vol. 208, 342-353. doi:10.1111/nph.13621.

Sridharan, K. (2018). Emerging Trends of Nanotechnology in Environment and Sustainability. A Review-Based Approach. Dubai: SpringerBriefs in Environmental Science.

The Greenhouse Effect. (2012). In US EPA Climate Change Indicators in the United States. $2^{\text {nd }}$ Edition, Washington, DC, USA: US EPA, available at: https://commons.wikimedia.org/wiki/File:Earth\%27s greenhouse effect (US EPA, 2012).p ng, accessed on 22 October 2019.

Willett, W., Rockström, J., Loken. B., Springmann, M., Lang, T., Vermeulen, S., Garnett, T., Tilman, D., DeClerck, F., Wood, A., Jonell, M., Clark, M., Gordon, L.J., Fanzo, J., Hawkes, C., Zurayk, R., Rivera, JA., De Vries, W., Majele Sibanda, L., Afshin, A., Chaudhary, A., Herrero, M., Agustina, R., Branca, F., Lartey, A., Fan, S., Crona, B., Fox, E., Bignet, V., Troell, M., Lindahl, T., Singh, S., Cornell, SE., Srinath Reddy, K., Narain, S., Nishtar, S., \& Murray, C.J.L. (2019). Food in the Anthropocene: The EAT-Lancet commission on healthy diets from sustainable food systems. The Lancet, Vol. 393, Issue $10170,447-492$. 